\title{
COP26: green technologies could turn the tide
}

\author{
The United Nations Climate Change Conference of the Parties, or COP26, will meet this month \\ in Glasgow. Countries will commit to new, ambitious targets for reducing emissions this decade. \\ Delivering on these promises will depend on the development and wide implementation of \\ green technologies.
}

As of this writing, the Climate Clock predicts that we have just under 7 years and 282 days to achieve zero greenhouse gas emissions, or face a high likelihood of irreversible climate damage. When heads of state and policymakers descend upon Glasgow this month for the 26th United Nations Climate Change Conference of the Parties (COP26), this deadline will - we hope - be on their minds.

Big things happen at the summit. The Paris Agreement, the first legally binding commitment to cut greenhouse gas emissions signed by almost every country in the world, was negotiated at the 2015 COP. The treaty aims to limit global warming to a critical threshold of $1.5^{\circ} \mathrm{C}$ from pre-industrial levels; a rise of even $2{ }^{\circ} \mathrm{C}$ is predicted to lead to much more severe climate impacts. If we stick to the emissions targets set in Paris, we are on track for more than $3{ }^{\circ} \mathrm{C}$ of warming by the end of the century.

Fortunately, under the Agreement, countries must update their emissions targets every 5 years to keep $1.5^{\circ} \mathrm{C}$ in reach. This year's summit is the first such update. Because our best window to reach net zero will likely close this decade, COP26 takes on a special urgency: ambitious targets will need to be set in Glasgow. It will likely be too late to slash emissions in 5 years.

Materials, of course, form the backbone of many sectors that need to be decarbonized, from the frontand-centre (energy production) to the less obvious (construction, transportation and infrastructure). In this month's pages and in a Collection, we feature several articles that highlight the central role of materials in the shift to greener technologies.

Solar energy is now cost-competitive with coal, thanks in part to emerging photovoltaic materials for solar cells. As Annamaria Petrozza and colleagues describe, chemically versatile materials such as metal halide perovskites are rapidly beginning to outperform established semiconductors. Still, we are nowhere near realizing their full conversion efficiency or operational stability, and the pace of research will need to keep up with climate goals.

To meet the demands of energy storage in a sustainable society - including grid-scale storage systems and electric vehicles - batteries must be made more cheaply with higher energy density and stability. Ce-Wen Nan and co-workers propose that inorganic-polymer solid-state electrolytes may reduce safety hazards and manufacturing costs associated with conventional Li-ion batteries. Robert Usiskin, Joachim Maier and colleagues lay out the case for $\mathrm{Na}$-based batteries to avoid the environmental and societal impacts and supply risks related to mining of Li. Fundamental research on corrosion and interfacial reactions is also needed to commercialize battery technologies, as Stefano Passerini, Arnulf Latz, Robert Kostecki and co-authors explain in their Review on rechargeable Li metal batteries.

Catalysts that use renewable feedstocks and maximize atom economy will aid the transition to carbon-neutral, energy-efficient chemical processes. Sharon Mitchell and Javier Pérez-Ramírez examine the potential of atomically precise catalytic clusters to improve the rational design of high-performance catalysts.

Materials engineering is at the heart of the construction industry, which is also responsible for a sizeable chunk of emissions. Decarbonizing construction is extremely ambitious, but, with creativity and resourcefulness, even concrete can be reimagined. The Olympics Park built for the 2012 London Games offers a glimpse into what construction could look like in a greener future. Buildings like the Olympic Stadium or Aquatics Centre were made with so-called sustainable concrete, in which recycled materials replaced mined ones. To cut unnecessary shipping, the concrete was all locally sourced and a ready-to-mix formulation was delivered by a single producer. Even the on-site mixing plant was placed next to a railroad to reduce the carbon footprint of transportation.

COP26 itself will be a carbon-neutral conference, at a venue that has won the Green Tourism award for committing to a low environmental impact of its operations. This alone cannot be its legacy; green technologies must fulfil the commitments made in Glasgow. Five years from now, we cannot be refreshing the Climate Clock, wondering where the time has gone. 